\title{
Educação à distância no ensino do diagnóstico por imagem em medicina veterinária: relato de experiência
}

\author{
Report of an experience using distance learning for diagnostic imaging teaching in \\ veterinary medicine
}

\section{Mauro Eduardo Soares de Oliveira ${ }^{\mathrm{I}}$ Rosana Zanatta $^{\mathrm{II}}$ Tilde Rodrigues Froes ${ }^{\mathrm{I}}$}

\section{RESUMO}

Este trabalho trata-se do relato da implantação e do desenvolvimento do Curso de Diagnóstico por Imagem (radiologia e ultrassonografia) abdominal em animais de companhia. O presente estudo teve como objetivo descrever a experiência da educação a distância (EaD como uma modalidade eficaz para proporcionar o ensino da subespecialidade) Diagnóstico por Imagem na medicina veterinária. Acredita-se que a EaD pode constituir-se em ferramenta pedagógica adequada para qualificar médicos veterinários que não têm acesso aos processos convencionais de pós-graduação, pois estão geograficamente dispersos ou mesmo não têm disponibilidade de afastar-se do seu cotidiano de vida profissional. Dessa forma, pode-se concluir que a referida técnica é uma estratégia pedagógica possível, confirmada pela certificação final em média de $70 \%$ dos discentes participantes.

Palavras-chave: educação a distância, veterinária, radiologia, ultrassonografia.

\section{ABSTRACT}

This study aims to report an experience of offering a course distance learning of small animal abdominal imaging diagnostic (radiology and ultrasonography). The purpose is to offer elements for a reflection on a conception distance education, as an efficient modality of education, aiming at enabling a teaching with quality to a determined clientele. Authors believe that distance learning is an adequate pedagogic tool to qualify veterinarians who have no access to traditional graduate studies, geographically disperse, who are unable to escape from the routine of their personal and professional lives; distance learning is an effective and possible pedagogical strategy, confirmed in the current case with final certification of $70 \%$ on average participators.

Key words: internet, education, distance, veterinary.

\section{INTRODUÇÃO}

A Educação a Distância (EaD) é tão antiga quanto os serviços postais, mas foi com a explosão da internet que ela se tornou mais atraente como forma de promover educação profissional continuada, uma necessidade emergente a partir de 1990 (ABREU et al., 2006). No mundo todo, a educação médico-veterinária a distância ganha mais espaço à medida que aumentam os programas de garantia de qualidade, em que estes passam por análises de seus recursos e de sua estruturação. No Brasil, o tema é relativamente recente, mas, em outros países da Europa, como a Inglaterra, e também nos Estados Unidos, esses programas existem há pelo menos cinco anos (BRODBELT 2009; SHORT et al., 2007). Entre as escolas que oferecem esses programas, a Royal College da Inglaterra se destaca, pois utiliza o recurso da internet para disponibilizar cursos de educação continuada, principalmente para pós-graduandos (SHORT et al., 2007).

Nos Estados Unidos, alguns sites, como, por exemplo, o www.vin.com, apresentam um grande contexto, sendo integradas, no mesmo site, diferentes escolas de medicina veterinária daquele país, proporcionando troca de experiências em diferentes especialidades, com múltiplos recursos de pesquisas, conferências on-line, estudos dirigidos, incentivando o ensino (PION, 2009). Na radiologia veterinária, sites de estudos e cursos também têm sido produzidos por diferentes escolas (VANDERWEERD et al., 2007; BRODBELT, 2009), sendo esta ainda uma disciplina

'Departamento de Medicina Veterinária, Universidade Federal do Paraná (UFPR), 80035-050, Curitiba, PR, Brasil. E-mail: tilde@ufpr.br. *Autor para correspondência.

"Departamento de Medicina Veterinária, Universidade de Cuiabá (UNIC), Cuiabá, MT, Brasil. 
privilegiada, pois pode-se transcrever as imagens digitalizando-as para o ensino. No Brasil, sites como TECvet têm sido criados com o objetivo de ensinar as práticas corretas de medicina veterinária, disponibilizando materiais e vídeos para graduandos e médicos-veterinários já formados (TIELLET et al., 2009).

A EaD surge como uma forma alternativa de educação aos indivíduos impossibilitados de estudar presencialmente, e algumas características fundamentais são a autonomia e independência com que o estudante tem de atuar, sendo ele o responsável pela organização do tempo dedicado ao estudo, a aquisição de conhecimentos e o desenvolvimento de sua aprendizagem (ARREDONDO, 2003). Os pesquisadores conseguiram demonstrar que essa forma de treinamento, o ensino com recursos de hipertexto, proporciona a interatividade e, como o estudo da radiologia é completamente visual, o método computadorizado proporciona uma real prática de ensino médico (GRUNEWALD et al., 2003).

MOTA et al (2006) acreditam que, na especialidade da radiologia, a digitalização é um recurso visto como solução de problemas em razão da pouca disponibilidade de material didático. Esses exames podem então ser digitalizados, assim como os exames de outras modalidades do diagnóstico por imagem e, posteriormente, trabalhados e formatados dentro de aulas, exercícios e casos, de forma que vários alunos possam ter acesso simultâneo com o uso de um computador, sem riscos ao acervo original. De qualquer forma, esse método de ensino tem características que devem ser salientadas, já que aprender pela internet é diferente de aprender lendo um livro ou mesmo na sala de aula (espaço e tempo), em que ocorre um contato verbal, visual e afetivo com o professor. Atualmente, a modalidade de EaD permite também um contato com o professor, sendo este na forma de encontros presenciais ou eletrônicos (vídeos chat) que oferecem oportunidades para a socialização e aprendizagem colaborativa (STEIL et al., 2005).

Outras modalidades do diagnóstico imaginológico também podem ser digitalizadas, para assim serem processadas e então estarem disponíveis ao ensino, entre elas, a ultrassonografia. Os vídeos dos exames podem ser adquiridos e disponibilizados, todavia, cabe salientar que para tal exame a prática da realização ultrassonográfica deve ser treinada, além da observação dos vídeos e das imagens dos exames (JOHNSON, 2008).

O trabalho teve por objetivos relatar as experiências obtidas durante o processo de criação e desenvolvimento de um curso de pós-graduação a distância, expor as particularidades do material de aprendizagem oferecido e descrever as características dos alunos e as formas de integração e avaliação.

\section{MATERIAL E MÉTODOS}

Foi realizada análise descritiva do método de EaD no ensino do diagnóstico por imagem, contendo desde as particularidades do material curricular oferecido, até as características dos alunos inscritos no programa em duas edições do curso, como: número de participantes, disposição geográfica, número de desistentes, concluintes e aprovados (aqueles que obtiveram média de notas acima de sete) e reprovados (aqueles que não atingiram a média sete). Também foram descritas as formas de interação distribuídas nos diferentes módulos do curso e como foram realizadas as avaliações.

\section{RESULTADOS}

A metodologia do programa foi desenvolvida por um professor de diagnóstico por imagem assessorado por uma equipe pedagógica. Essa equipe constitui-se de um tutor e mais um assessor, que ficava responsável pela inserção do material em vídeo da plataforma e dos vídeos de chats. Os conteúdos da plataforma sofreram um processo de adequação à linguagem de EaD (Figura 1), priorizandose a dialogicidade e o enriquecimento visual.

O material visual foi constituído de vídeoaulas, intervenções especialmente gravadas pelo professor e que direcionaram o aluno na execução do plano pedagógico. No curso, disponibilizaram-se também vídeos com a realização da técnica de um exame ultrassonográfico e imagens estáticas e dinâmicas das duas modalidades dos exames imaginológicos propostos. As imagens radiográficas constituíam-se da digitalização de filmes radiográficos da casuística e do acervo do professor responsável. Depois de digitalizadas, as imagens foram processadas no Adobe ${ }^{\circledR}$ Photoshop $^{\circledR}$, permitindo assim uma melhor qualidade de interpretação.

O curso foi dividido em quatros módulos, sendo um módulo introdutório, que proporcionou ao aluno o conhecimento da metodologia de EaD e promoveu a sua adaptação à comunidade virtual do curso. Nesse momento, o aluno, já utilizando a plataforma, pôde interagir com os diferentes meios que lhe foram proporcionados e começar a acessar os ambientes de discussões e dialogicidade. Nessa parte do curso, o aluno pôde decidir se queria ou não continuar com essa forma de ensino, pois esta exige 


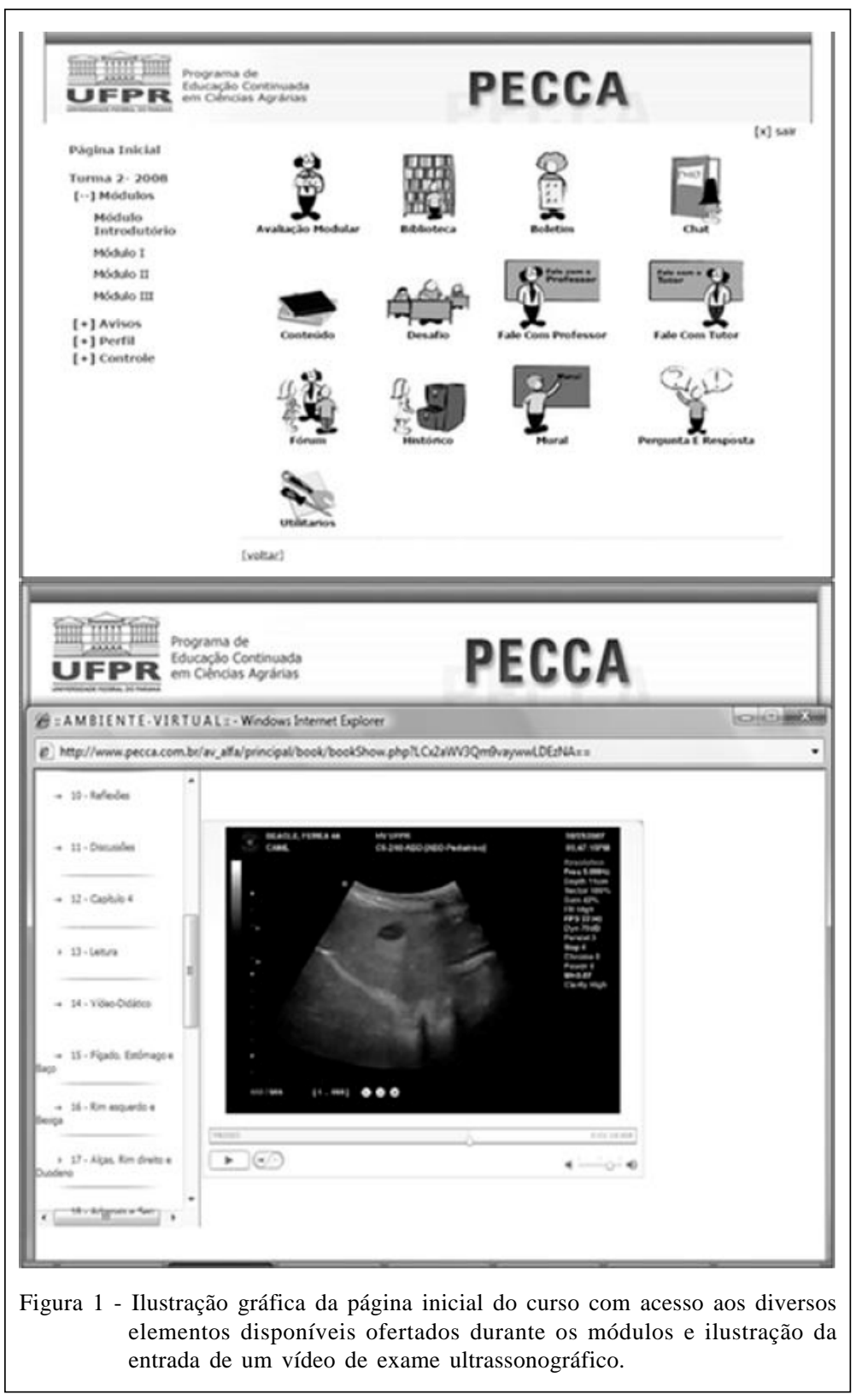

certo tempo e dedicação. Além disso, o aluno também se apresentou e expressou as suas expectativas sobre o aprendizado, que foram de: obter conhecimento de indicações das diferentes técnicas, conhecimento de processamento e obtenção das imagens, princípios de interpretação e interpretação das principais enfermidades da cavidade abdominal, os quais poderiam ser úteis em seu afazer futuro ou ainda lhe proporcionar alternativa de trabalho.

O módulo I, com o conteúdo da programação pedagógica, foi segmentado em: princípios físicos e de interpretação das imagens radiográficas e ultrassonográficas, técnicas de realização dos exames, como manipular um equipamento de ultrassonografia, revisão da anatomia abdominal radiográfica e ultrassonográfica, e diagnóstico por imagem do trato urinário caudal (bexiga e uretra). Ainda nesse módulo foi disponibilizado ao aluno um vídeo de execução e técnica do exame ultrassonográfico normal de cão macho e fêmea, em que eram demonstradas as manobras manuais para execução dos cortes sonográficos e, posteriormente, a imagem ultrassonográfica produzida por esse corte. O módulo II constituiu-se de: Diagnóstico por Imagem do trato urinário cranial (rim e 
ureter), genital masculino e feminino e baço. O módulo III foi composto de: diagnóstico por imagem do fígado, vias biliares, pâncreas, cavidade abdominal, espaço retroperitoneal (glândulas adrenais) e trato gastrintestinal.

Ressalta-se que todo esse material didático era constituído de textos, figuras, esquemas, fluxogramas, filmes radiográficos digitalizados, vídeos de exames ultrassonográficos e vídeo-aulas, nas quais o professor era filmado comentando os principais pontos a serem estudados e revisados, passando assim a sua experiência pessoal sobre o assunto. No arquivo "biblioteca" do site, eram disponibilizados artigos científicos, em português e inglês, de revistas renomadas. Os artigos cobriam os assuntos descritos e discutidos nos módulos e eram de leitura livre, geralmente acessados quando o discente quisesse se aprofundar ainda mais em temas que gostasse ou precisasse.

Como método de diálogo, foi disponibilizado o acesso a fóruns de discussões ao aluno, e as perguntas, para cogitação, eram postadas no início de cada módulo. Existia também uma sessão de perguntas ao professor, na qual a resposta era dada ao aluno em até 24 horas, e as dúvidas sanadas eram postadas online. Nas duas turmas, os fóruns de discussão on-line foram dispostos de forma que o aluno pudesse se expressar de acordo com o assunto proposto nos módulos, sendo a resposta direta um fator de avaliação. A descrição da porcentagem dos alunos em seu envolvimento nos fóruns de discussão é apresentada na figura 2, e variou de perfeita, aluno participando em todos os questionamentos, até a não participação. Destaca-se que essa atuação também foi utilizada como uma das notas para aprovação.

Foram programados também vídeo-chats, em horários pré-determinados, para que o aluno tirasse suas dúvidas diretamente com o professor, com acesso simultâneo, e o diálogo foi uma forma de se conhecer ainda mais o perfil do professor frente a diferentes casos e assuntos, geralmente o aluno trazia as dúvidas dos seus casos para serem sanadas. Cerca de 35\% dos alunos participaram dos vídeo-chats e estes não eram obrigatórios.

No acompanhamento pedagógico do aluno, este era permanentemente monitorado, sendo realizado um controle do número de acessos e do tempo permanecido on-line, da participação nos fóruns e das respostas dos desafios, sendo esse sistema realizado por uma central de computação e por um tutor. Duas aulas presenciais foram realizadas durante o período do curso, com atividades programadas de treinamento de leitura de filmes radiográficos, realização de exames ultrassonográficos em cães e gatos normais e casos da rotina hospitalar, permitindo um contato dos alunos com dificuldades reais de realização e interpretação dos exames. Na segunda aula, os alunos ainda puderam realizar treinamento de ultrassonografia intervencionista, praticando punções por agulha fina em moldes preparados. Durante as aulas presenciais, os alunos também puderam trazer os seus casos clínicos para discussão e interpretação. As aulas presenciais duraram oito horas cada. Cerca de $40 \%$ da turma estiveram presentes nas aulas presenciais, e esses alunos se desenvolveram mais, - análise subjetiva-, quando comparado aos outros, e obtiveram um crescimento maior nas inter-relações pessoais proporcionadas pela plataforma, participaram mais dos vídeo-chats e ainda desenvolviam os desafios de casos clínicos com maior qualidade de interpretação e redação de laudos. As aulas presenciais foram agendadas no meio para o final do curso, e os alunos já tinham adquirido conhecimento teórico prévio sobre o conteúdo.

A avaliação dos alunos era obrigatória e individual, sendo realizada em quatro etapas: notas dadas em relação à frequência de acesso no site, notas dadas em relação ao número de participação nos fóruns de discussão on-line, notas dadas sobre o número de acertos de questões escritas de múltipla escolha e notas referentes à descrição de laudos radiográficos e ultrassonográficos dispostos sobre forma de casos clínicos na plataforma, vale ressaltar que as imagens ultrassonográficas dos casos clínicos eram vídeos de exames sonográficos. Para todos esses dados, obtevese então uma nota, que variou de zero a 10, e no final de cada módulo era realizada uma média dessas notas. Para aprovação, o aluno deveria obter uma média final maior ou igual a sete. Essa forma de avaliação seguiu as formatações preconizadas pelo Ministério da educação.

Os alunos eram predominantemente graduados há mais de cinco anos, sendo atuantes em diferentes especialidades; todavia, muitos eram clínicos ou cirurgiões de animais de companhia que queriam se aprimorar no Diagnóstico por Imagem, para solucionar as questões de seus casos clínicos. Em torno de 25, eram alunos que estavam iniciando na área, querendo então se aprofundar nessa especialidade. Participou do curso um total de 31 alunos na turma de 2007, e um total de 29, na turma de 2008. Em ambas as turmas os alunos eram de diferentes regiões do Brasil, sendo a maioria proveniente do Estado do Paraná. Ainda com relação à localização dos alunos, 23 (40\%) eram do Paraná, sete (12\%) eram do Rio de janeiro, seis (11\%) eram de Santa Catarina, cinco (9\%) eram de São Paulo, 


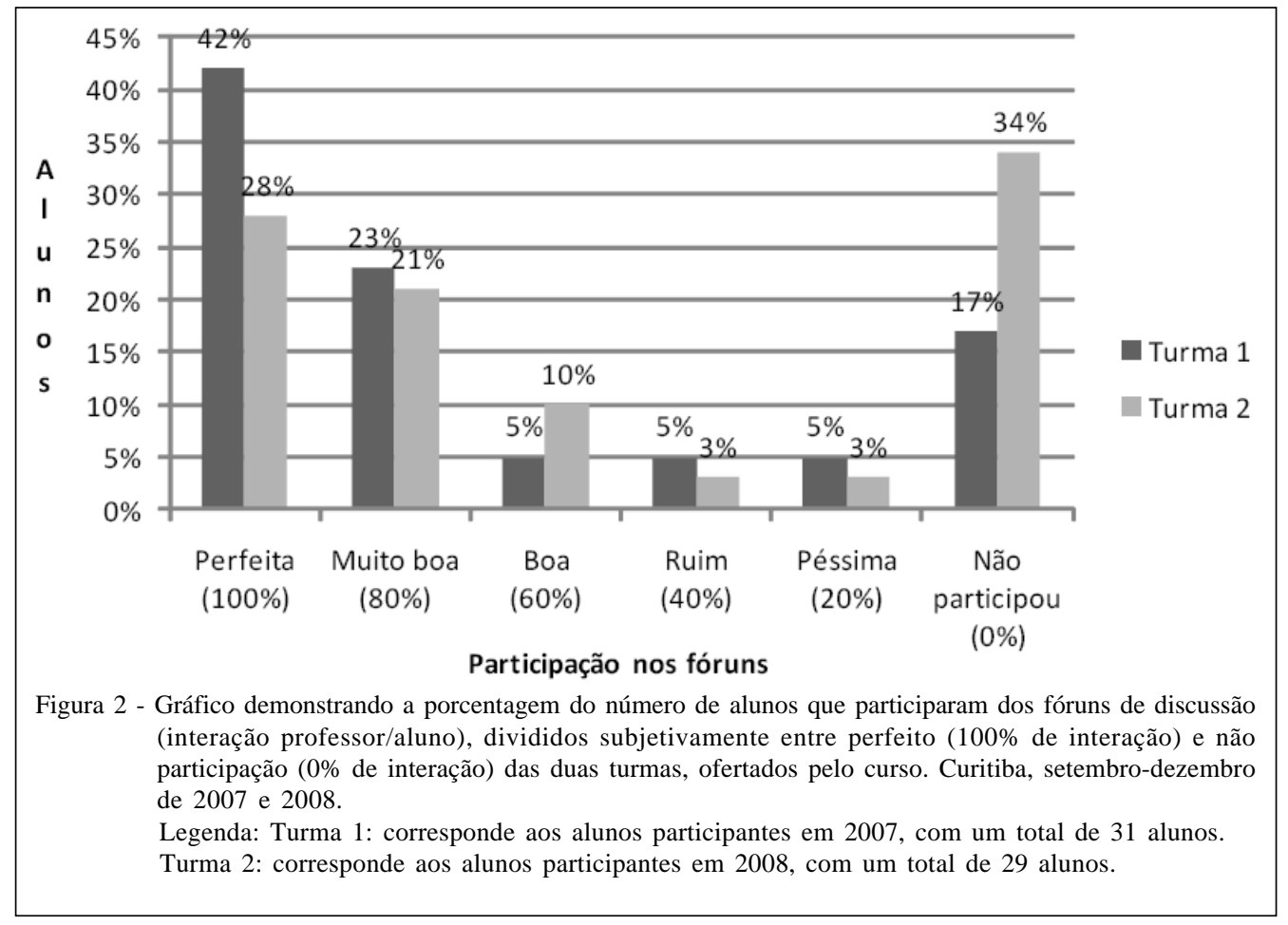

quatro (7\%) eram do Rio Grande do Sul, três (5\%) eram da Bahia, dois (3\%) eram do Distrito Federal, dois (3\%) eram de Minas Gerais, um (2\%) era do Amazonas, um (2\%) era do Maranhão e um (2\%) era do Ceará. Além disso, um (2\%) aluno era dos Estados Unidos da América e um (2\%) não relatou sua localização.

$\mathrm{Na}$ primeira turma (setembro-dezembro 2007), 23 (77\%) alunos concluíram e foram aprovados com média superior a sete, sete $(22,5 \%)$ concluíram o curso, mas não obtiveram nota para aprovação, e um (0.5\%) aluno desistiu no início do segundo módulo. Na segunda turma (setembro-dezembro 2008), 21 (72\%) alunos concluíram o curso e foram aprovados, sendo seis $(20,6 \%)$ reprovados, e dois $(6,8 \%)$ desistiram entre o primeiro e o segundo módulo.

\section{DISCUSSÃO}

Corroborando a literatura consultada, verificou-se que é possível realizar essa metodologia de EaD na medicina veterinária brasileira, subespecialidade radiologia e ultrassonografia. Além disso, como previamente citado por alguns autores (GRUNEWALD et al., 2003), essa especialidade é privilegiada para essa forma de ensino, já que o conhecimento baseia-se em visibilizar imagens de diferentes exames. Em consonância com MOTA et al. (2006), acredita-se que a digitalização das imagens deve ser vista como um recurso de aprendizado, pois as imagens podem ser trabalhadas em forma de exercícios e casos, e vários alunos podem ao mesmo tempo estudar esses casos, sendo então uma excelente forma de aprendizado contínuo, até porque a radiologia é muito relacionada a acurácia visual, e então o método computadorizado proporciona uma real prática de ensino. Neste estudo, as imagens radiográficas analógicas foram digitalizadas, e verificou-se que, uma vez que o profissional saiba como trabalhar com softwares de imagem, essa digitalização pode ser feita, sem grande perda da qualidade da imagem, e assim estas podem ser utilizadas para interpretação.

Apesar da boa qualidade das imagens, dos vídeos de como se realizar os exames sonográficos e das imagens dinâmicas dos exames sonográficos, a EaD aparentemente não apresentou perfeita eficiência no ensino completo da ultrassonografia, pois esse exame é basicamente operador dependente, e a prática em sua realização é aprendida com um treinamento mais intenso, com tutoria próxima, além da observação dos vídeos e casos disponibilizados sob a forma de EaD. Essa dificuldade foi confirmada nas aulas presenciais, nas quais se pôde verificar realmente a dificuldade de alguns membros do corpo discente em adquirir e processar imagens sonográficas para um diagnóstico perfeito. Pela EaD, é possível que o aluno tenha uma boa base sobre a técnica ultrassonográfica e a 
visibilização das imagens em vídeos e estáticas; entretanto, o seu aprendizado só será completo com o seu esforço contínuo e com estágios. Nesses estágios, o aluno deverá realizar e observar os exames ultrassonográficos, os quais são considerados importantes para um bom desempenho nessa modalidade imaginológica (JOHNSON, 2008; MONTEIRO, 2009).

Entretanto, abre-se uma discussão e dúvida de que provavelmente nem mesmo cursos presenciais teóricos proporcionam um conhecimento adequado e completo para médicos-veterinários tornarem-se ultrassonografistas competentes; todavia, essa modalidade de formação ainda precisa ser investigada.

Apesar da dificuldade real do aprendizado completo na técnica ultrassonográfica, foi possível confirmar as vantagens da EaD como forma de ensino, por exemplo, pela possibilidade de ampliar e democratizar o conhecimento, principalmente em um país do tamanho do Brasil, pois, nas duas turmas, observaram-se alunos de diferentes regiões do país (CHRISTANTE, 2003).

A EaD dá a chance ao aluno de ter uma maior flexibilidade para os estudos e a possibilidade de conciliar, de forma relativamente fácil, as demandas advindas das diferentes áreas de família, estudos, trabalho e lazer (ABRAHANSON, 2007). No entanto, de acordo com os números de desistentes e não aprovados, nas turmas, percebe-se que nem todos os alunos são suficientemente determinados e disciplinados ao estudo. Ou seja, as limitações recorrentes (de não fazerem os exercícios recomendados, participarem dos fóruns de discussões e laudarem os casos clínicos propostos) evidenciam que o aluno deve ter um compromisso e uma disciplina para seguir os planos de estudos propostos e cumprir os prazos de avaliações.

Assim como COOPERMAN (2007), constatamos que uma das partes consideradas mais importantes é o relacionamento interpessoal via web provocado pelos fóruns de discussão, no qual os alunos podem relatar suas experiências, denominada a parte "viva” do curso. No ensino convencional, os alunos são tratados na coletividade, no que se refere ao ritmo, tempo e material educacional. Na EaD, o contato tutor/aluno/professor é maior, e percebe-se que é necessário para o professor saber trabalhar com diferenças, sob o ponto de vista de experiência profissional,vida, cultura e habilidades, principalmente nas discussões de fóruns.

O professor e o tutor devem adotar estratégias educacionais, nas quais o respeito a essa característica humana se realize, pois, diante da diversidade, é preciso atenção para valorizar as diferenças, estimular ideias, opiniões e atitudes, desenvolver a capacidade de aprender a aprender e de aprender a pensar, assim como levar o aluno a obter o controle consciente do aprendido, retê-lo e aplicá-lo em sua rotina profissional. Faz-se então um paralelo, e acredita-se que o acompanhamento ao aluno nesses casos é diferenciado e quase que personalizado no processo de ensino-aprendizagem, exigindo que o professor/tutor seja organizado, estruture uma lógica de trabalho e defina códigos de orientação pessoal, assim ocorre uma maior exigência, porém claramente é uma vantagem na maneira de ensinar (CHRISTANTE, 2003).

Os fóruns de discussão permitiram também um efeito de sociabilização, apesar de ser inegável que, na educação à distância, esse efeito é aparentemente falho, quando comparado ao ensino convencional; no entanto, este pode ser minimizado pelos encontros presenciais, nos quais foi possível um maior contato, e a identificação do grau de envolvimento e participação nas tarefas, auxiliando posteriormente as avaliações. Vale ressaltar que nem todos os alunos estão dispostos a essa sociabilização, o que influencia negativamente essa forma de avaliação do individuo com o seu engajamento no curso. A troca de mensagens também foi uma forma encontrada pelo aluno de sanar suas dúvidas, sendo verificada menor frequência em comparação aos fóruns de discussão.

As vídeo-aulas introdutórias de cada módulo e os vídeo-chats permitem ao aluno ter uma ideia sobre o perfil do professor, diminuindo a distância e a ansiedade de um trabalho mediado pela tecnologia, dando-lhe uma abordagem mais humana ao curso. Acredita-se que essas tecnologias são importantíssimas também para dar mais vida a um contexto tecnológico de aprendizado. Todavia, as aulas presenciais também determinaram o melhor efeito de sociabilização, sendo importantes em determinada parte do curso. Os alunos que estiveram presentes sem dúvida interagiram ainda melhor na plataforma e nos outros recursos de sociabilização.

\section{CONCLUSÕES}

Com essa experiência, confirma-se que, apesar das limitações discutidas e das restrições expostas no que tange ao ensino específico da ultrassonografia veterinária, acredita-se que a $\mathrm{EaD}$ pode ser realizada na medicina veterinária, mais especificamente na subespecialidade Diagnóstico por Imagem, sendo uma alternativa na forma de realização dos cursos de especialização no Brasil.

Ciência Rural, v.40, n.7, jul, 2010. 


\section{REFERÊNCIAS}

ABRAHANSON, S. How we learn: concepts, insights, and rationale for integration. Journal Veterinary Medical Education, v.34, n.3, p.213-216, 2007. Disponível em: <http:/ /www.jvmeonline.org/archive/>. Acesso em: 23 nov. 2009. doi: 10.3138/jvme.34.3.213

ABREU, R.A.S.; COSTA, A.M.N. Mudanças geradas pela Internet no cotidiano escolar: as reações dos professores. Paidéia, v.16, n.34, p.193-203, 2006. Disponível em: <http:/ /www.scielo.br/pdf/paideia/v16n34/v16n34a07.pdf >. Acesso em: 23 nov. 2009.

ARREDONDO, S.C. Formación/Capacitatión del professorado para trabajar en EAD. Educar, v.21, n.1, p.13-27, 2003 Disponível em: <http://www.educaremrevista.ufpr.br/ numero_21.htm >. Acesso em: 25 nov. 2009.

BRODBELT, D. Evidence based veterinary medicine. Obtido em site: RVC continuing Professional Development. Disponível em: <www.rvc.ac.uk/CPD>. Online. Acesso em: 23 nov. 2009.

CHRISTANTE, L. et al. O papel do ensino a distância na educação médico continuada: uma análise crítica. Revista da Associação Médica Brasileira, v.49, n.3, p.326-329, 2003. Disponivel em: <http://www.virtual.epm.br/material/tis/ amb.pdf>. Acesso em: 25 nov. 2009.

COOPERMAN, L. Instructional design for online course development. Journal Veterinary Medical Education, v.34, n.3, p.238-242, 2007. Disponível em: <http://www.jvmeonline.org/ archive/>. Acesso em: 23 nov. 2009. doi: 10.3138/jvme.34.3.238.

GRUNEWALD M. et al. COMPARE radiology creating an interactive web-basead training program for radiology using an authoring system. Academic Radiology, v.10, n.5, p.543-553, 2003. Disponível em: <http://www.academicradiology.org/>. Acesso em: 23 nov. 2009. doi: 10.1016/S1076-6332(03)80065-X.

JOHNSON, E. Ultrasound teleradiology is (largely) a fack!. Obtido em site ANIMALINSIDES. Disponível em: http:/ /www.animalinsides.com. Online. Acesso em: 22 nov. 2009.
LAMB, C.R. et al. Errors in radiographic interpretation made by veterinary students. Journal of Veterinary Medical Education, v.34, n.2, p.157-159, 2007. Disponível em: <http:/ /www.jvmeonline.org/archive/>. Acesso em: 23 nov. 2009. doi: 10.3138/jvme.34.2.157.

MONTEIRO, S.C. Avaliação interobservador do aprendizado em ultrassonografia abdominal do sistema urogenital, adrenais e espaço retroperitonial de cães. 2009. 109f. Dissertação (Mestrado) - Curso de Pós-graduação em Ciências Veterinárias, Universidade Federal do Paraná.

MOTA, T.D. et al. Ferramenta de ensino a distância para o Departamento de Radiologia da Universidade Federal do Rio de Janeiro. Revista da Imagem, v.28, n.3, p.147-154, 2006. Disponivel em: <http://www.spr.org.br/revista_da_imagem.php>. Acesso em: 25 nov. 2009.

PION, P.D. Veterinary information network. Obtido em site VIN.COM. Disponível em: http://www.vin.com/Members/. Online. Acesso em: 22 de nov. 2009.

SHORT, N. et al. Veterinary e-CPD: A new model for providing online continuing professional development for veterinary profession. Journal of Veterinary Medical Education.v.34, n.5, p.689-694, 2007. Disponível em: <http://www.jvmeonline.org/ archive/>. Acesso em: 23 nov. 2009. doi: 10.3138/jvme.34.5.689.

STEIL, A.V. et al. Atitudes com relação à educação a distância em uma universidade. Psicologia em Estudo, v.10, n.2, p.253262, 2005. Disponível em: <http://www.scielo.br/ scielo.php?script=sci_serial\&pid=1413-7372>. Acesso em: 23 nov. 2009.

TIELLET, C.A.F. et al. Tecvet hipervídeos. Obtido em site. TECVET.com.br. Disponível em: <http://www.ufsm.br/ tielletcab/TECvet/>. Online. Acesso em: 22 nov. 2009.

VANDERWEERD, J.M.E. et al. Teaching veterinary radiography by e-learning versus structured tutorial: A randomized, single-blinded controlled trial. Journal Veterinary Medical Education, v.34, n.2, p.160-167, 2007. Disponível em: <http://www.jvmeonline.org/archive/>. Acesso em: 23 nov. 2009. doi: 10.3138/jvme.34.160. 